\title{
Meta-analysis of a master mimicker: endobronchial lipoma
}

\author{
Padmastuti Akella $^{1}$, Vishal Jindal ${ }^{1}$, Bharat Singh Bhandari ${ }^{1}$, Ahmad D. Siddiqui $^{2}$ \\ ${ }^{1}$ Department of Internal Medicine, ${ }^{2}$ Department of Hematology and Oncology, Saint Vincent Hospital, Worcester, MA, USA \\ Contributions: (I) Conception and design: P Akella, V Jindal, AD Siddiqui; (II) Administrative support: AD Siddiqui; (III) Provision of study materials \\ or patients: All authors; (IV) Collection and assembly of data: P Akella, V Jindal, BS Bhandari; (V) Data analysis and interpretation: P Akella, V \\ Jindal; (VI) Manuscript writing: All authors; (VII) Final approval of manuscript: All authors. \\ Correspondence to: Padmastuti Akella. Department of Internal Medicine, Saint Vincent Hospital, 123 Summer Street, Worcester, MA 01608, USA. \\ Email: stuti.akella@gmail.com.
}

\begin{abstract}
Background: Endobronchial lipomas (ELs) are extremely rare benign tumors that account for $0.1-$ $0.4 \%$ of all bronchial tumors. Our study aims to better characterize these lesions based on their baseline demographic characteristics, size, location, association with smoking and establish a treatment modality of choice for such tumors.

Methods: We conducted a retrospective meta-analysis of 29 studies of EL reported from 1994 till present. These 29 studies yielded 36 patient encounters which were included in our study. Categorical outcomes were compared between study groups using chi-square test. $\mathrm{P}$ value $<0.05$ was considered statistically significant.

Results: Our study has shown that smaller lesions more likely to be ELs or benign lung tumors. Eighty percent of ELs had a size $<1.5 \mathrm{~cm}(\mathrm{P}=0.056)$ and the other tumor types had a size $\geq 1.5 \mathrm{~cm}$.

Conclusions: These tumors are difficult to diagnose due to their nonspecific presenting complaints unless pulmonologists maintain a high index of suspicion. Treatment options such surgical resection (SR) or bronchoscopic resection (BR) are available and interventions should be planned on a case-by-case basis by a multidisciplinary team.
\end{abstract}

Keywords: Endobronchial lipoma (EL); lung neoplasm; bronchoscopy; cough; bronchiectasis; chronic obstructive pulmonary disease (COPD)

Submitted Mar 25, 2019. Accepted for publication Aug 23, 2019.

doi: $10.21037 /$ cco.2019.08.17

View this article at: http://dx.doi.org/10.21037/cco.2019.08.17

\section{Introduction}

A variety of benign and malignant tumors arise from the lung, around $95 \%$ are carcinomas, $5 \%$ are bronchial carcinoids, and $2 \%$ to $5 \%$ are mesenchymal in origin (1). Intrathoracic lipomas are tumors composed exclusively of mature adipose tissue which rarely occur within the lungs $(0.1-0.5 \%$ of benign lung tumors) (2). Intrathoracic lipomas can be classified into five groups: endobronchial, parenchymal, pleural, mediastinal and cardiac (3). Endobronchial lipomas (ELs) originate from the fat cells located in the peribronchial tree and occasionally the submucosal tissue of main bronchi. These lesions usually are pedunculated with a narrow stalk and may extend between the cartilaginous rings into the peritracheal tissue $(1,2,4)$. A lipoma consists of mature fatty tissue covered with normal bronchial epithelium (2). Squamous metaplasia, fibrous, glandular tissue, areas of cartilage or osseous metaplasia can also be found in the lipoma; a pathologist must use a variety of differentials to rule out atypical lipomatous tumors and well-differentiated liposarcomas (1).

ELs are rare tumors and hence can be missed easily (5). When missed, these rather benign lesions can cause a high degree of morbidity and mortality (6). The late diagnosis of benign neoplasms can lead to irreversible pulmonary damage (7). Symptoms may be generalized and mimic chronic pulmonary diseases, lowering our degree of suspicion and increasing the chances of missing such lesions. These tumors can present with signs and symptoms of productive cough, hemoptysis, wheezing, obstruction, 
Table 1 Baseline characteristics and demographics of the adults in the study

\begin{tabular}{|c|c|}
\hline Demographics & Percentages (\%) \\
\hline \multicolumn{2}{|l|}{ Age (years) } \\
\hline$\leq 40$ & 8.3 \\
\hline$\geq 41$ & 91.7 \\
\hline \multicolumn{2}{|l|}{ Gender } \\
\hline Male & 72.2 \\
\hline Female & 22.2 \\
\hline \multicolumn{2}{|l|}{ Histopathology } \\
\hline EL & 72.2 \\
\hline Other tumors & 27.8 \\
\hline \multicolumn{2}{|l|}{ Location of tumor } \\
\hline Right & 47.2 \\
\hline Left & 44.4 \\
\hline Bilateral & 8.3 \\
\hline \multicolumn{2}{|l|}{ Size of tumor } \\
\hline$<1.5 \mathrm{~cm}$ & 13.8 \\
\hline$\geq 1.5 \mathrm{~cm}$ & 38.8 \\
\hline \multicolumn{2}{|l|}{ Treatment } \\
\hline SR & 41.2 \\
\hline $\mathrm{BR}$ & 58.8 \\
\hline \multicolumn{2}{|l|}{ Presenting complaints } \\
\hline Recurrent pneumonia & 11.1 \\
\hline Chest pain tightness & 16.6 \\
\hline Thoracic pain & 2.7 \\
\hline Palpitations & 2.7 \\
\hline Acute cough & 16.7 \\
\hline Persistent cough & 27.8 \\
\hline Productive cough & 30.6 \\
\hline Dry cough & 19.4 \\
\hline Fever & 22.2 \\
\hline Hemoptysis & 16.7 \\
\hline Stridor & 2.7 \\
\hline Exertional dyspnea & 38.9 \\
\hline Acute pneumonia & 13.8 \\
\hline
\end{tabular}

EL, endobronchial lipoma; SR, surgical resection; BR, bronchoscopic resection. recurrent pneumonias and bronchiectasis (6). These lesions can cause bronchial obstruction which can lead to distal parenchymal lung damage over months to years. They often present with a clinical picture of asthma and can be misdiagnosed as malignancies. These lesions can cause post-obstructive pneumonias in patients leading to multiple repetitive antibiotics (7). Given, the high degree of lung injury caused by these benign lesions, it is important to focus our efforts on maintaining a high degree of suspicion. Currently in literature, only case reports and case series are published, our study aims to better characterize these lesions based on their size, location, association with smoking and gender and establish a treatment modality of choice for such tumors.

\section{Methods}

\section{Study selection}

The literature and database searches identified 29 studies since 1994 for inclusion. An online search of MEDLINE and Ovid yielded a total of 161 records. Manual bibliographic searches of identified articles and publications resulted in an addition of 15 records. Manuscripts were screened following the removal of duplicates and applying the inclusion criteria. Keywords including 'EL, hamartoma, leiomyoma' were searched in the discussion and tumor histopathology sections. We selected 29 articles for our retrospective analysis after excluding 147 articles as per our exclusion criteria (e.g., incorrect tumor histopathology, unavailability of tumor histopathology reported). These 29 studies yielded 36 patient encounters which were included in our study.

\section{Epidemiology}

Baseline characteristics included age, gender, presenting complaints, size of the tumor, tumor histopathology, smoking history, history of pulmonary diseases [asthma, chronic obstructive pulmonary disease (COPD), bronchiectasis] (Table 1). Additional variables such as chest radiographs, computed tomography (CT) scans, location of the tumor and treatment method were included. Follow-ups were studied as office visits, follow-up CT scans and chest radiographs done for suspicious disease recurrence.

\section{Statistical methods}

Descriptive analysis was carried out by mean and 
standard deviation for quantitative variables, frequency and proportion for categorical variables. Non-normally distributed quantitative variables were summarized by median and interquartile range (IQR). Data was also represented using appropriate diagrams such as bar graphs, pie charts and box plots. Categorical outcomes were compared between study groups using chi-square test. $\mathrm{P}$ value $<0.05$ was considered statistically significant. IBM SPSS version 22 was used for statistical analysis (IBM Corp. Released 2013. IBM SPSS Statistics for Windows, Version 22.0, Armonk, NY, USA).

\section{Results}

\section{Clinical characteristics}

A total of 36 patients were included in the final analysis. In our study we showed that $91.7 \%$ of our patients had an age greater than or equal to 41 and a majority of patients were male [ $\mathrm{n}=26(72.2 \%)$ males, $\mathrm{n}=8(22.2 \%)$ females] as demonstrated by previous studies (6). We found $36.1 \%$ of patients with ELs were reported smokers, and only 5.6\% of them were non-smokers/never smokers. Obesity and smoking are considered risk factors, although there are no conclusive studies showing a causative relation (8).

Presenting symptoms included productive cough $(\mathrm{n}=11,30.6 \%)$, persistent cough $(\mathrm{n}=10,27.8 \%)$, exertional dyspnea $(\mathrm{n}=14,38.9 \%)$, fever $(\mathrm{n}=8,22.2 \%)$, dry cough $(\mathrm{n}=7$, $19.4 \%)$, acute cough $(\mathrm{n}=6,16.7 \%)$ and hemoptysis $(\mathrm{n}=6$, $16.7 \%$ ). Cough is the most common form presentation and progressive dyspnea, hemoptysis, recurrent pneumonias were the other commonly seen presenting complaints (8). Patients are erroneously diagnosed with bronchial asthma, delaying the diagnosis of these types of lesions $(4,5,8,9)$. A minority $(n=6)$ of patients reported chest pain and chest tightness. A few $(n=5)$ presented with acute and/or recurrent pneumonias. Atypical presentations such as thoracic pain, palpitations and stridor were reported too. Eighty percent of patients had abnormalities on chest radiograph (e.g., atelectasis, consolidation, or mass) and $58.3 \%$ of them got a chest radiograph prior to their diagnosis (3). Ninetyseven point two percent underwent a CT scan of the chest to establish diagnosis. As previously mentioned, CT scans are highly specific and sensitive to adipose tissue density helping with early diagnosis (Table 2).

Eleven point one percent reported a previous history of COPD while $8.3 \%$ reported a history of asthma. Others had a history of chronic cystic bronchiectasis $(n=2,5.4 \%)$ and pneumothorax ( $\mathrm{n}=1,2.8 \%$ ) prior to diagnosis.

Majority of the tumor histopathology were ELs ( $n=26$, $72.2 \%)$, hamartomas $(n=5,13.9 \%)$ and leiomyomas $(n=3$, $8.3 \%)$. Our study has shown that smaller lesions are more likely to be ELs or benign lung tumors. Eighty percent of ELs had a size $<1.5 \mathrm{~cm}(\mathrm{P}=0.056)$ and the other tumor types had a size $\geq 1.5 \mathrm{~cm}$. Forty-seven point two percent ELs were found in the right lung (main bronchus, lobular bronchus and peripheral to segmental bronchus) in comparison $44.4 \%$ were discovered in the left lung. These lesions were found in the first three subdivisions of the tracheobronchial tree (6). Eight point three percent of ELs were interestingly seen in bilateral lung lobes.

Flexible bronchoscopy was used to locate the tumor in $77.8 \%$, while $13.9 \%(\mathrm{n}=5)$ underwent a rigid bronchoscopy. Fifty-eight point eight percent $(\mathrm{n}=20)$ underwent bronchoscopic resection (BR) of the EL with use of either argon plasma coagulation (APC) or Nd-YAG laser or electrocautery while $41.2 \%(n=14)$ ultimately underwent surgical resection (SR) for treatment of the EL (Figure 1).

\section{Outcome}

BR was successful in $75.0 \%$. For the one unsuccessful patient, the location of the tumor was the lobar bronchus of the left upper lobe (LUL) (4). Due to the acute angulation of the LUL of the patient, the mass could not be grasped with using any kind of endobronchial tools as reported (4). The patient underwent an open thoracotomy and LUL lobectomy (4). No mortality occurred in the 28 patient outcomes reported. We compared all the variables such as smoking, location, gender, age, presenting symptoms, tumor histopathology with final outcome and there was no significant difference.

\section{Follow-up and recurrence}

Duration of follow-up ranged from 1 to 38 months' postresection. Relief of symptoms was noted post-resection/ surgery on follow-up clinic visits. In one case recurrence in the form of leiomyoma was diagnosed by chest CT and bronchoscopy seventeen months post-resection.

As the lesion was in the proximal left main bronchus, the patient underwent left pneumonectomy. The pathology showed a leiomyoma confined within the bronchial cartilage. No complications were noted on 17-month follow-up post procedure. In one patient, the postoperative course was characterized by fever and purulent bronchial 
Table 2 Composite results of study selection

\begin{tabular}{|c|c|c|c|c|c|c|}
\hline Year & Age & Histopathology & Location & Tumor size & $\begin{array}{c}\text { Treatment for the } \\
\text { tumor }\end{array}$ & Outcome \& follow-up \\
\hline 2008 & 62 & EL & RLL & NR & SR & Successful, post-op pneumonia treated with Abx \\
\hline 2013 & 63 & EL & LLL & $2.0 \mathrm{~cm}$ & SR & Successful \\
\hline 2007 & 56 & EL & RUL & NR & $\mathrm{BR}$ & Successful \\
\hline 2014 & 43 & EL & RLL & NR & NR & NR \\
\hline 2015 & 64 & EL & RUL & NR & SR & NR \\
\hline 2004 & 47 & EL & $\mathrm{RM}$ & $1.5 \mathrm{~cm} \times 1.0 \mathrm{~cm}$ & SR & Successful, 5 months \\
\hline 2015 & 68 & SEL & RLL & NR & SR & NR \\
\hline 2005 & 43 & EL & $\mathrm{RM}$ & NR & SR & NR \\
\hline 2014 & 63 & EL & RLL & NR & BR & Successful, 6 months \\
\hline 2013 & 35 & EL & $\mathrm{RM}$ & $2.0 \mathrm{~cm}$ & $\mathrm{BR}$ & NR \\
\hline 2016 & 60 & MEL & RLL & $1.2 \mathrm{~cm}$ & SR & Successful, 12 months \\
\hline 1999 & 62 & EL & LLL & $3.0 \mathrm{~cm} \times 1.2 \mathrm{~cm} \times 1.4 \mathrm{~cm}$ & SR & Successful \\
\hline 2014 & 61 & EL & LLL & $0.8 \mathrm{~cm} \times 0.7 \mathrm{~cm} \times 1.1 \mathrm{~cm}$ & BR & Successful, 3 months \\
\hline 2009 & 53 & EL & $\mathrm{BI}$ & NR & SR & Successful, 6 months \\
\hline 2006 & 51 & $\mathrm{~L}$ & RUL & $1.6 \mathrm{~cm}$ & $\mathrm{BR}$ & Successful, 38 months \\
\hline 2014 & 63 & $\mathrm{LH}$ & RLL & $1.5 \mathrm{~cm} \times 1.0 \mathrm{~cm}$ & BR & Successful, 1 month \\
\hline 2017 & 63 & EL & LM & NR & $\mathrm{BR}$ & Successful \\
\hline 2014 & 73 & EL & LM & NR & $\mathrm{BR}$ & Successful, 1 month \\
\hline 2013 & 65 & EL & RUL & $2.2 \mathrm{~cm} \times 1.8 \mathrm{~cm} \times 1.1 \mathrm{~cm}$ & SR & Successful, 11 months \\
\hline 1994 & 68 & EL & LUL & $1.0 \mathrm{~cm}$ & SR & Successful \\
\hline 2004 & 56 & $\mathrm{LH}$ & $\begin{array}{c}\mathrm{BI} \text { and } \\
\mathrm{RLL}\end{array}$ & NR & SR & NR \\
\hline 2011 & 48 & EL & $\mathrm{RM}$ & NR & $\mathrm{BR}$ & Successful, 1 month \\
\hline 2017 & 63 & EL & LLL & $1.2 \mathrm{~cm} \times 1.0 \mathrm{~cm} \times 1.5 \mathrm{~cm}$ & $\begin{array}{l}\text { Biopsy, no } \\
\text { resection }\end{array}$ & NR \\
\hline 2013 & 62 & EL & LUL & NR & BR & Successful, 1.5 months \\
\hline
\end{tabular}

BR includes APC, snare electrocautery, Nd-YAG laser therapy; SR includes thoracotomy, lobectomy, pneumonectomy, wedge resection, bronchotomy. EL, endobronchial lipoma; SEL, submucosal endobronchial lipoma; MEL, myxoid endobronchial lipoma; L, leiomyoma; $\mathrm{H}$, hamartoma; LH, lipomatous hamartoma; RM, right maintstem bronchus; LM, left mainstem bronchus; RUL, right upper lobe; RML, right middle lobe; RLL, right lower lobe; BI, bronchus intermedius; LUL, left upper lobe; LLL, left lower lobe; NR, not reported; BR, bronchoscopic resection; APC, argon plasma coagulation; SR, surgical resection. 

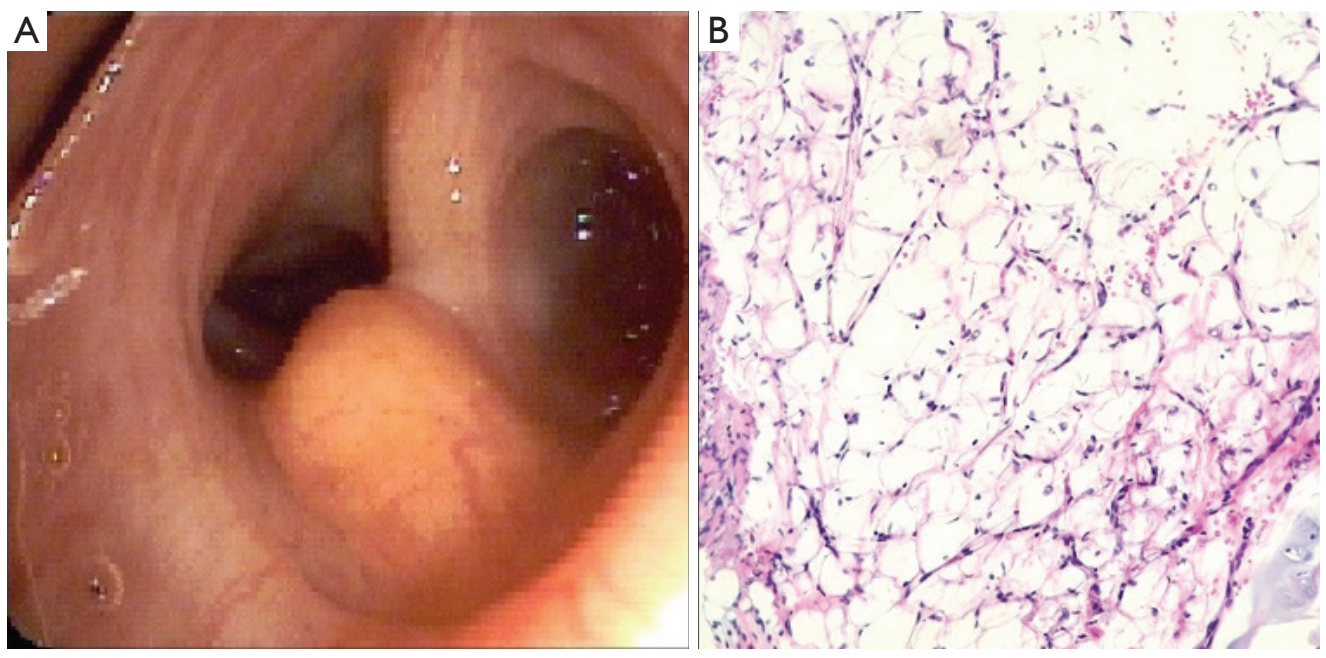

Figure 1 Bronchoscopic image and histopathology. (A) The finding of the lesion in situ via the bronchoscope, revealing a 3 mm polypoid tumor in the RLL bronchus and EL was suspected; (B) a pathological examination revealed a polypoid tumor, covered with stratified ciliated epithelial cells, which consisted of mature adipocytes; cell scale bar: $7.92 \mathrm{~cm} \times 15.90 \mathrm{~cm}$; dyeing method: black and white. RLL, right lower lobe; EL, endobronchial lipoma.

secretions, controlled with broad-spectrum antibiotics and discharged home after 6 days (9). In another patient, post-snare cautery of the lipoma, a coughing bout during the bronchoscopy caused the tumor to slip into the left mainstem bronchus. Hypoxemia ensued requiring endotracheal intubation, followed by a rigid bronchoscopy to extract the already resected tumor mass. Immediately after the extraction, oxygenation improved, the patient was extubated and discharged home the next day. At follow-up the patient had complete resolution of cough (10).

\section{Discussion}

ELs are rare benign tumors of the lung which arise from the submucosal layer of the bronchus. Only $5 \%$ of all lung tumors are benign. Ninety percent of benign lesions are adenomas or hamartomas. Although lipomas are a common tumor of the body, ELs are extremely rare. Their incidence has been reported to range from $0.1-0.5 \%$ in all lung tumors $(3,6,11)$. These lesions have been reported to have no premalignant connotation (3).

In our study, $36 \%$ of the patients reported tobacco dependence prior to the diagnosis of the tumor. Case reports claim that smoking and obesity are significant risk factors $(8,11)$. Our study comprised $72 \%$ male patients with EL which adheres to previous reports that mention a male predominance with this condition (8). Most of our study patients were aged 41 years or older. Studies have shown a peak incidence between the fifth and sixth decades of life (8). The most common presenting complaints in our study were exertional dyspnea (38.9\%), sputum production (30.6\%), persistent cough $(27.8 \%)$, fevers $(22.2 \%)$, hemoptysis (16.7\%) and chest pain (16.6\%) $(3,6,7,9,12)$.

Radiological modalities such as chest radiographs and CT chest play a key role in establishing diagnosis. In our study, $80 \%$ of patients had abnormalities on chest radiograph (e.g., atelectasis, consolidation, or mass) and $58.3 \%$ of them got a chest radiograph prior to their diagnosis. CT scan is highly specific and sensitive for adipose density in the lesion (13). $97.2 \%$ of our study patients underwent a CT scan of the chest to establish diagnosis. These tumors are often diagnosed late, due to their slow growth and unspecific symptoms, of which cough is the most common. A delayed diagnosis leads to late treatment, increasing morbidity due to the distal obstruction caused by the lesion. Presenting complaints and physical examination findings can be nonspecific, cross-sectional imaging modalities such as a CT chest can help decisions about further management strategies (14). Conventional radiography is often nonspecific and shows post-obstructive changes such as atelectasis, pneumonia and bronchiectasis $(15,16)$. Multidetector CT (MDCT) scan with isotropic resolution and thin slice thickness is the imaging modality of choice. It defines intraluminal and extraluminal extent well along 
with the tumor density (17). The presence of fat attenuation narrows down the differential diagnoses to: pure EL, which has homogeneous fat attenuation, fibrolipomatous tumour, which has soft tissue attenuation with islands of fat; and hamartomas, which show fat density alternating with calcific foci $(2,17)$. Ahn et al. reported that hamartomas can have connective tissue stroma, lymphoid tissue and smooth muscle components within the soft tissue attenuation suggesting a hamartoma $(2,18-20)$.

Current therapeutic interventions include SR and endoscopic/BR (4,21-23). The majority of ELs occur in the first three subdivisions of the tracheobronchial tree where there is abundant cartilage and adipose tissue (24). In our study, $47.2 \%$ of ELs were found in the right lung (main bronchus, lobular bronchus and peripheral to segmental bronchus) while $44.4 \%$ were discovered in the left lung. SR with bronchoplastic reconstruction has long been the standard treatment (4). Forty-one point two percent $(n=14)$ of study patients underwent SR for treatment of the EL. Flexible bronchoscopy is essential as it identifies the location of lesion and facilitates the collection of tissue for histopathology (13). Flexible bronchoscopy was used to locate the tumor in $77.8 \%$ of our study patients, while $13.9 \%(n=5)$ underwent a rigid bronchoscopy for the collection of tissue for histopathology. After the NdYAG laser was first applied by Toty and colleagues in 1978, bronchoscopic excision has seen new techniques applied to treat ELs (25). Fifty-eight point eight percent $(n=20)$ of study patients underwent BR of the EL with use of either APC or Nd-YAG laser or electrocautery. Generally, bronchoscopic removal of endobronchial tumor is preferable when the tumor is small or pedunculated $(26,27)$. Our study has shown that smaller lesions are more likely to be ELs and we showed that $80 \%$ of ELs have a size $<1.5 \mathrm{~cm}(\mathrm{P}=0.056)$. Early recognition and diagnosis of these benign lesions may allow for conservative treatment and excellent patient outcome in the long run (2). None except one patient was reported to have a recurrence of the lesion. Options include laser ablation, APC, electrocauterization, cryorecanalization and electrosurgical snaring (24). Removal of an EL using a flexible bronchoscopic electrosurgical snaring does not require general anesthesia and is less invasive than a surgical excision (23). There are, however, several instances where SR is preferred such as difficult definite diagnosis, complicated peripheral destructive lung disease due to long-term atelectasis or pneumonia, subpleural lipomatous disease or expected technical difficulty due to multidirectional development of the tumor (4). While many treatment options are available, intervention should be planned on a case-by-case basis by a multidisciplinary team.

\section{Conclusions}

EL is a benign and rare neoplasm of the respiratory tract. Despite its benign nature, high degree of suspicion is required due to nonspecific symptoms. If missed can lead to deleterious and irreversible complications like bronchial occlusion, recurrent pneumonias, bronchiectasis and permanent damage to lung parenchyma. ELs are generally managed by endoscopic or SR. Endoscopic resection being less invasive, and both diagnostic and therapeutic, is the primary treatment of choice. Complete surgical excision is reserved for tumors which outgrows bronchial walls and becomes irresectable endoscopically. Therefore, a multidisciplinary approach is crucial for successful management.

\section{Acknowledgments}

Funding: None.

\section{Footnote}

Conflicts of Interest: All authors have completed the ICMJE uniform disclosure form (available at http://dx.doi. org/10.21037/cco.2019.08.17). The authors have no conflicts of interest to declare.

Ethical Statement: The authors are accountable for all aspects of the work in ensuring that questions related to the accuracy or integrity of any part of the work are appropriately investigated and resolved. The study was approved by Saint Vincent Hospital, Department of Medicine, Worcester, MA 01608.

Open Access Statement: This is an Open Access article distributed in accordance with the Creative Commons Attribution-NonCommercial-NoDerivs 4.0 International License (CC BY-NC-ND 4.0), which permits the noncommercial replication and distribution of the article with the strict proviso that no changes or edits are made and the original work is properly cited (including links to both the 
formal publication through the relevant DOI and the license). See: https://creativecommons.org/licenses/by-nc-nd/4.0/.

\section{References}

1. Kumar V, Abbas AK, Fausto N, et al. Robbins and Cotran pathologic basis of disease. 8th ed. Philadelphia: Elsevier Health Sciences, 2009:1464.

2. Ko JM, Jung JI, Park SH, et al. Benign tumors of the tracheobronchial tree: CT-pathologic correlation. AJR Am J Roentgenol 2006;186:1304-13.

3. Pollefliet C, Peters K, Janssens A, et al. Endobronchial lipomas: rare benign lung tumors, two case reports. J Thorac Oncol 2009;4:658-60.

4. Choi JC, Yu CM, Ryu YJ, et al. The role of endoscopic surgery for completely obstructive endobronchial benign tumor. Korean J Intern Med 2006;21:15-9.

5. Liam CK, Jayalakshmi P, Kumar G, et al. Endobronchial lipoma simulating bronchogenic carcinoma. Postgrad Med J 1994;70:668.

6. Muraoka M, Oka T, Akamine S, et al. Endobronchial lipoma: review of 64 cases reported in Japan. Chest 2003;123:293-6.

7. Ouadnouni Y, Bouchikh M, Bekarsabein S, et al. Endobronchial lipoma a rare cause of pleural empyema: a case report. Cases J 2009;2:6377.

8. Triviño A, Mora-Cabezas M, Vallejo-Benitez A, et al. Endobronchial lipoma: a rare cause of bronchial occlusion. Arch Bronconeumol 2013;49:494-6.

9. Filosso PL, Giobbe R, Mossetti C, et al. Hemoptysis caused by an endobronchial lipoma. J Thorac Cardiovasc Surg 2008;135:954-5.

10. Madan K, Agarwal R, Bal A, Gupta D. Bronchoscopic management of a rare benign endobronchial tumor. Rev Port Pneumol 2012;18:251-4.

11. Schraufnagel DE, Morin JE, Wang NS. Endobronchial lipoma. Chest 1979;75:97-9.

12. Guelbenzu Zazpe JJ, Ramírez Gil E, Vilá Mayo E. Talking about endobronchial lipoma. Arch Bronconeumol 2015;51:251-2.

13. Sivapalan P, Gottlieb M, Christensen M, et al. An obstructing endobronchial lipoma simulating COPD. Eur Clin Respir J 2014. doi: 10.3402/ecrj.v1.25664.

Cite this article as: Akella P, Jindal V, Bhandari BS, Siddiqui AD. Meta-analysis of a master mimicker: endobronchial lipoma. Chin Clin Oncol 2020;9(2):11. doi: 10.21037/cco.2019.08.17
14. Tronco Alves GR, Pasquali M, de Silva RV, et al. An infrequent cause of persistent cough: endobronchial lipoma. Ann Saudi Med 2013;33:636-7.

15. Sarioglu N, Susur A, Goksel T, et al. An unexpected cause of hemoptysis: endobronchial lipomatous hamartoma. Med Arch 2014;68:65-6.

16. On R, Kushima H, Ishii H, et al. Endobronchial lipoma: the diagnostic benefit of computed tomography findings. Intern Med 2018;57:285-6.

17. Liew CJ, Tham KY, Poh AC, et al. Endobronchial lipoma. Singapore Med J 2017;58:510-1.

18. Farsad GR, Makoui C. Endobronchial lipoma. Am Surg 1981;47:236-8.

19. Wilson RW, Kirejczyk W. Pathological and radiological correlation of endobronchial neoplasms: part I, benign tumors. Ann Diagn Pathol 1997;1:31-46.

20. Ahn JM, Im JG, Seo JW, et al. Endobronchial hamartoma: CT findings in three patients. AJR Am J Roentgenol 1994;163:49-50.

21. Galvez C, Sesma J, Bolufer S, et al. Single-incision videoassisted anatomical segmentectomy with handsewn bronchial closure for endobronchial lipoma. Ann Transl Med 2016;4:284.

22. Cavaliere S, Foccoli P, Farina PL. Nd:YAG laser bronchoscopy. A five-year experience with 1,396 applications in 1,000 patients. Chest 1988;94:15-21.

23. Flores-Franco RA, González-Calzadillas LF, Cota-Castro S. Successful endoscopic resection of an endobronchial lipoma using a percutaneous gastrostomy snare device. Arch Bronconeumol 2018;54:235-6.

24. Yun SC, Na MJ, Choi E, et al. Successful removal of endobronchial lipoma by flexible bronchoscopy using electrosurgical snare. Tuberc Respir Dis (Seoul) 2013;74:82-5.

25. Toty L, Personne C, Colchen A, et al. Bronchoscopic management of tracheal lesions using the neodynium yttrium aluminium garnet laser. Thorax 1981;36:175-8.

26. Chakraverty SC, Rafferty PR. Laser therapy for endobronchial tumours. Scott Med J 1992;37:141-3.

27. Magro CM, Ross P Jr. Endobronchial mimics of primary endobronchial carcinoma: a clinical study of 25 cases. Can Respir J 2005;12:123-7. 